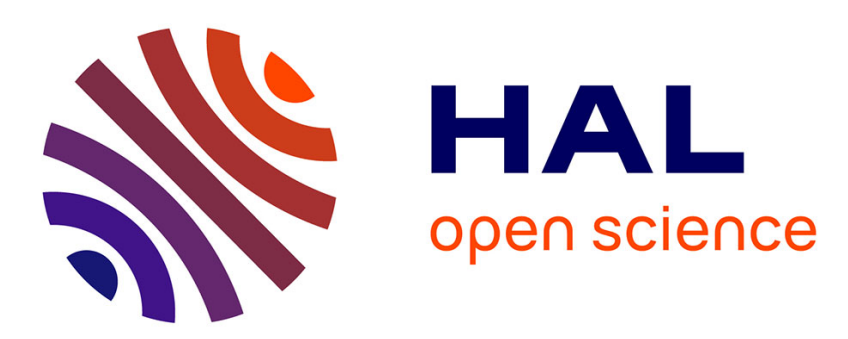

\title{
Heat treatment structure modification of wrought nickel based superalloy and its creep resistance
}

\author{
J. Zrník, V. Vrchovinský
}

\section{To cite this version:}

J. Zrník, V. Vrchovinský. Heat treatment structure modification of wrought nickel based superalloy and its creep resistance. Journal de Physique IV Proceedings, 1993, 03 (C7), pp.C7-283-C7-288. 10.1051/jp4:1993745 . jpa-00252163

\section{HAL Id: jpa-00252163 https://hal.science/jpa-00252163}

Submitted on 1 Jan 1993

HAL is a multi-disciplinary open access archive for the deposit and dissemination of scientific research documents, whether they are published or not. The documents may come from teaching and research institutions in France or abroad, or from public or private research centers.
L'archive ouverte pluridisciplinaire HAL, est destinée au dépôt et à la diffusion de documents scientifiques de niveau recherche, publiés ou non, émanant des établissements d'enseignement et de recherche français ou étrangers, des laboratoires publics ou privés. 


\section{Heat treatment structure modification of wrought nickel based superalloy and its creep resistance}

\section{J. ZRNÍK and V. VRCHOVINSKÝ}

Technical University of Košice, Department of Material Science Park, komenského 11, 04002 Košice, Slovakia

Abstract

The effect of structure modification on creep characteristics of nickel based superalloy EI $698 \mathrm{VD}$ has been studied. The substructure changes were caused by variation of the temperature and time parameters in solution treatments and in precipitation annealing process of the alloy. Through the change of gamma prime morphology and extent of $\mathrm{M}_{23} \mathrm{C}_{6}$ carbide precipitation on grain boundaries the creep strength and plastic characteristics were influenced. Significant decrease of lifetime was accompanied with remarkable increase of relative proportion of intercrystalline cleavage fracture mechanisms.

Introduction

Nickel based superalloys are considered to become the main stream of the aircraft gas turbine materials. EI 698 VD alloy is a designation assigned to the $\mathrm{Ni}$ superalloy used mainly for the compressor parts of turbines. It has been reported that creep rupture properties of superalloys were influenced by heat treatment. It is well-known that high temperature strength of precipitation hardened $\mathrm{Ni}$ based superalloys depends directly on the volume fraction and morphology of gamma prime particles as well as on distribution and shape of carbide particles [1]. The grain size is one of the important structural factors affecting the creep rupture properties of these alloys as well [2]. An optimal structural state of this type of alloys may be reached by way of multistage heat treatment methods making considerable demands on time and energy.

The aim of this study was to investigate the effect of modified heat treatment programs and to evaluate the influence of these treatment adjustments on microstructural and mechanical properties at elevated temperature.

Material and experimental procedures

The chemical composition of the EI 698 VD alloy used is in Tab.1 The following programs of heat treatment were tested to influence the alloy microstructure.

State 1 - wrought conditions only (initial state)

State $2-1100^{\circ} \mathrm{C} / 8 \mathrm{~h} / \mathrm{air}-1000^{\circ} \mathrm{C} / 4 \mathrm{~h} / \mathrm{air}-775^{\circ} \mathrm{C} / 16 \mathrm{~h} / \mathrm{air}$

State $3-1100^{\circ} \mathrm{C} / 8 \mathrm{~h} / \mathrm{air}-800^{\circ} \mathrm{C} / 16 \mathrm{~h} / \mathrm{air}$

State $4-1100^{\circ} \mathrm{C} / 8 \mathrm{~h} / \mathrm{air}-1050^{\circ} \mathrm{C} / 4 \mathrm{~h} / \mathrm{air}-775^{\circ} \mathrm{C} / 16 \mathrm{~h} / \mathrm{air}$

State $5-1100^{\circ} \mathrm{C} / 8 \mathrm{~h} / \mathrm{air}-950^{\circ} \mathrm{C} / 4 \mathrm{~h} / \mathrm{air}-775^{\circ} \mathrm{C} / 16 \mathrm{~h} / \mathrm{air}$

The state 2 corresponds to heat treatment processing according to the manufacturer's recommended instructions. The substructure development in individual stages of heat treatment was studied by means of thin foils and extraction replicas. EDX analysis of thin foils and replicas was employed to identify carbide particles in a matrix and on grain boundaries. Creep rupture tests were conducted at $650^{\circ} \mathrm{C}$ in the range of testing stresses $580-734 \mathrm{MPa}$. Test specimens were rods of gage length $30 \mathrm{~mm}$ and gage diameter $5.0 \mathrm{~mm}$.

SEM analyses of fracture surfaces of ruptured specimens were used to define fracture characteristics and identify rupture mechanisms in the process of creep tests. A statistical analysis of the relative 
proportions of fracture mechanisms taking place in the process of initiation and propagation of fracture cracks was carried out on individual fracture surfaces. Mechanisms and the extent of deformation during creep was investigated by means of substructural studies in the underfracture zone of ruptured specimens.

Results

\section{Microstructure}

The heat treatment programs used resulted in the development of different final specimen substructures. Fig.1 and 2 show final microstructures of the initial state and state 2 .

Microstructural and substructural changes were observed in succession in individual annealing stages. The austenite grain size of the final state was the same in all cases and the mean diameter of grains was determined to be approximately $\mathrm{d}_{\mathrm{m}}=0.065 \mathrm{~mm}$. Coarser block-like MC carbides arising as a product of eutectic reaction during solidification of the alloy were present in the matrix. No changes of their size, morphology or distribution were observed during the process of solution annealing. By EDX analysis these were identified as carbides of complex composition [3]. The level of annealing temperatures in individual stages affected mainly the size of gamma prime particles and the extent of $\mathrm{M}_{23} \mathrm{C}_{6}$ carbide precipitation and size on grain boundaries. It was revealed that air cooling after first stage annealing did not guarantee a homogenous solid solution. Gamma pxime particles of approximate size $20 \mathrm{~nm}$ were precipitated out in the matrix during the cooling process. They were available for modification in the subsequent annealing process. The second stage of annealing proved to be of decisive importance for the formation of different substructural characteristics. The upward change of temperature by $50^{\circ} \mathrm{C}$ in the second stage of annealing (state 4) produced a substructure identical to that developed by annealing at $1100^{\circ} \mathrm{C}$, i.e. this temperature corresponded more probably to the temperature of solution annealing suitable for this alloy. Fig. 3 shows the final microstructure of state 4 after additional annealing at $775^{\circ} \mathrm{C}$. The size of gamma prime particles was approximately $50 \mathrm{~nm}$. No size heterogenity was observed. In case of annealing in the second stage where the annealing temperature was $950^{\circ} \mathrm{C}$, this change was manifested as a considerable increase of gamma prime size (ca $d_{m}=200$ $\mathrm{nm}$ ) and a growth of $\mathrm{M}_{23} \mathrm{C}_{6}$ carbides on grain boundaries. The temperature $950^{\circ} \mathrm{C}$ appears to be critical for precipitation of gamma prime particles and for growth of $\mathrm{M}_{23} \mathrm{C}_{6}$ carbides. These are accompanied by solute depletion of the surrounding matrix and result in the appearence of a denuded zone around grain boundaries. A final annealing at $775^{\circ} \mathrm{C}$ gives rise to additional gamma prime precipitation as well as new $\mathrm{M}_{23} \mathrm{C}_{6}$ carbide particles on the grain boundaries. The final microstructure after this heat treatment shows a bimodal distribution of gamma prime particles in the matrix and carbide size heterogenity embedded on grain boundaries, as shown in Fig.4. The uniform gamma prime precipitation of ca $50 \mathrm{~nm}$ in the matrix and the more pronounced precipitation of $\mathrm{M}_{23} \mathrm{C}_{6}$ carbides along the grain boundaries, illustrated in Fig.5 shows the final substructure of just a two stage heat treatment process.

\section{Mechanical properties}

The results of tensile tests at ambient temperature are summarized in Table 2 . All states comply with the requirement $R p 0,2$. States 1 and 2 are the only ones complying with the requirement $R m$. Plastic properties are, however, less satisfactory for all states except for the state 3 .

Fig. 6 shows the results of creep tests. The required lifetime of 
this alloy at $600^{\circ} \mathrm{C}$ with an applied stress equal to $706 \mathrm{MPa}$ is minimally 50 hrs. The Fig. 6 diagram shows lifetime values $t_{f}$ of individual states for the required stress obtained by linear extrapolation. The shortest lifetime corresponds to only a two stage heat treatment. The highest value of ductility / $\mathrm{A}_{5} /$ corresponding to such a heat treatment contrasts with expectations.

Fractography results

Metallography examination of the fracture surfaces revealed the initiation of fracture processes on grain boundaries and the presence of intercrystalline cleavage cracks in all specimens. Propagation of cracks continued by transgranular brittle cleavage and the final rupture resulted in transgranular ductile crack growth, as illustrated in Fig.7. Table 3 shows the results of a statistical fractographic analysis of fracture mechanisms for individual states. The results of fracture observation revealed that coarse aggregates of primary MC carbides considerably affect crack initiation and its propagation.

Study of deformation processes in the vicinity of fracture surfaces points to localization of deformation into slip bands in individual grains, Fig.8. A modifying effect of gamma prime particle size on dislocation glide mechanisms was revealed. Fig.9 shows narxow stacking faults inside the larger gamma prime particles, probably developed due to local stress concentrations at these particles.

Discussion

Microstructural studies and results of creep tests suggest that changing the heat treatment procedure of EI 698 VD alloys, either by changing the temperature level in the second stage annealing, or by modification of the overall process, results in changes of alloy structural characteristics reflected in strength characteristics derived from creep tests. The structure with a bimodal gamma prime morphology and grain boundaries suitably strengthened by the presence of carbide particles appeared more advantageous in view of reaching the required high temperature properties.

It was found that the temperature $1100^{\circ} \mathrm{C}$ is insufficient to achieve total homogenization of this alloy, mainly as far as the coarser MC carbide were concerned. Another factor which may influence the precipitation process is the rate of cooling from the solutionizing temperature. The air cooling rate failed to produce a homogenous solution before the additional precipitation treatment.

Results of substructure investigations revealed that annealing temperatures in the interval $900-1000^{\circ} \mathrm{C}$ must be used to achieve a bimodal gamma prime morphology. Selection of the temperature level must take into account the simultaneous $\mathrm{M}_{23} \mathrm{C}_{6}$ carbide precipitation which may contribute decisively to the decrease of plastic properties at elevated temperature because of the decrease of cohesive strength of the grain boundaries. Annealing below $900^{\circ} \mathrm{C}$ ensures a uniform distribution and size of gamma prime particles in the matrix. However, no positive effect on deformation properties of the alloy was observed due to the unfavourable influence of intensive carbide precipitation on grain boundaries. Veakening of boundaries may be intensified by the decrease of plastic ability of the matrix due to the increased volume fraction of gamma prime phase, suggested also by the occurence of transcrystalline cleavage fracture facets on fracture surfaces.

The fractographic evaluations of fracture surfaces do confirm the fact that am unfavourable combination of precipitation effect throughout the volume and on grain boundaries manifests itself by the increased sensitivity to intercrystalline crack initiation.

The results obtained by introducing heat treatment modifications into the thermal processing regime of EI 698 VD Ni based superalloys lead to the most important piece of knowledge that even slight changes 
of the prescribed heat treatment process affect considerably the microstructural characteristics and lead eventually to the decrease of creep strength and plastic characteristics at elevated temperatures.

Conclusion

The proposed changes of heat treatment of EI 698 VD alloy resulted in altered substructual changes and were reflected directly in values of creep strength and lifetime for individual heat treatment process. The increase of temperature by $50^{\circ} \mathrm{C}$ in the second stage of annealing suppressed the development of bimodal gamma prime morphology. The temperature decrease by $50^{\circ} \mathrm{C}$ resulted in formation of a similar bimodal microstructure to that of the prescribed heat treatment. However, this modification affected considerably the course of grain boundary precipitation. The modification of the heat treatment by omission of the second stage annealing failed and was accompanied by a remarkable increase of the relative proportion of intercrystalline cleavage fracture during the creep test.

\section{References}

[1] WALIS R.A., BHOVAL P.R.: Superalloys 1988, Proceedings of TMS International Symposium, Varrendale, (1988), p.525

[2] YOSHIBA M. et al.: Transactions ISIJ, Vol.28, 1988, p.B-22

[3] ZRNIK J.: Habilitation Thesis, TU Košice,1990

Table 1. Chemical composition of EI 698 VD alloy

\begin{tabular}{|ccccccccccccc|}
\hline Prvok & C & Cr & Al & Ti & Mo & Nb & Fe & Si & Mn & S & P & Ni \\
\hline Vt.\% & 0,08 & 13 & 1,3 & 2,3 & 2,8 & 1,8 & $\max$ & max & max & max & max & \\
& & 16 & 1,7 & 2,7 & 3,2 & 2,2 & 2,0 & 0,6 & 0,4 & 0,007 & 0,015 & zV \\
\hline
\end{tabular}

Table 2. Mechanical properties

\begin{tabular}{|llrrr|}
\hline State & $\begin{array}{c}\mathrm{R}_{\mathrm{R}}{ }^{0,2}, \\
{[\mathrm{MPa}]}\end{array}$ & $\begin{array}{r}\mathrm{R}_{\mathrm{m}} \\
{[\mathrm{MPa}]}\end{array}$ & $\begin{array}{c}\mathrm{A}_{5} \\
{[\%]}\end{array}{ }^{[\%]} \mathrm{Z}$ \\
\hline 1 & 711 & 1155 & 5,7 & 11,7 \\
2 & 781 & 1161 & 14,7 & 11,2 \\
3 & 792 & 1103 & 19,7 & 10,4 \\
4 & 793 & 1083 & 15,9 & 7,6 \\
5 & 714 & 1033 & 13,9 & 7,1 \\
stated & 706 & 1127 & 17,0 & 19,0 \\
\hline
\end{tabular}

Table 3. Creep test conditions and fracture mechanisms portion /FMP/

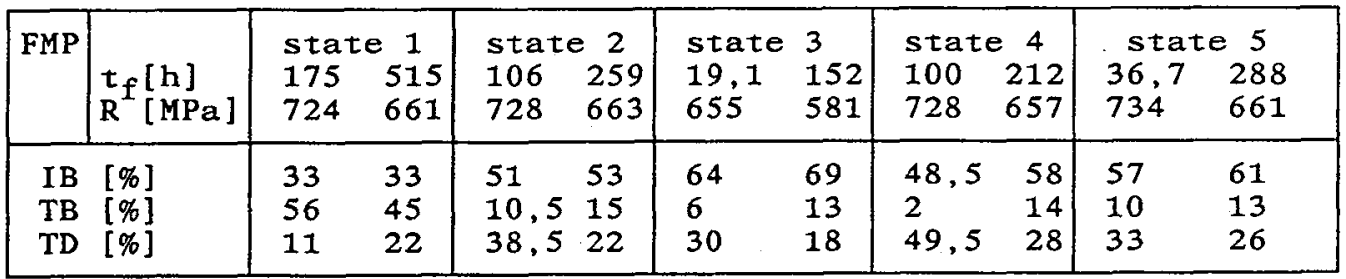

IB - intercrystalline brittle fracture

TB - transcrystalline brittle fracture

TD - transcrystalline ductile fracture 


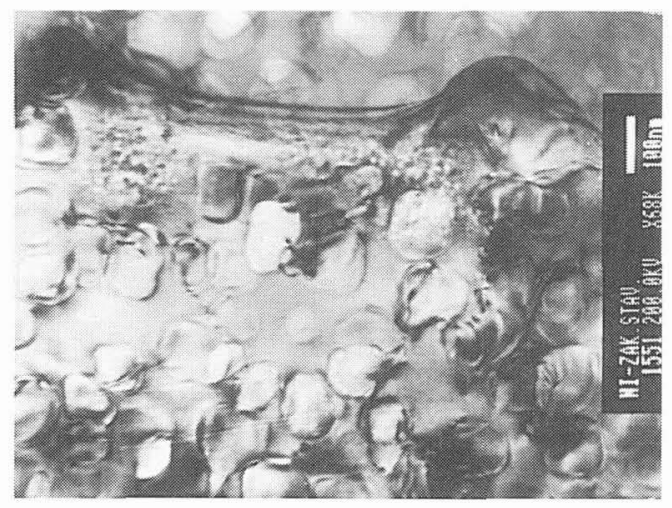

Fig.l Microstructure of wrought alloy

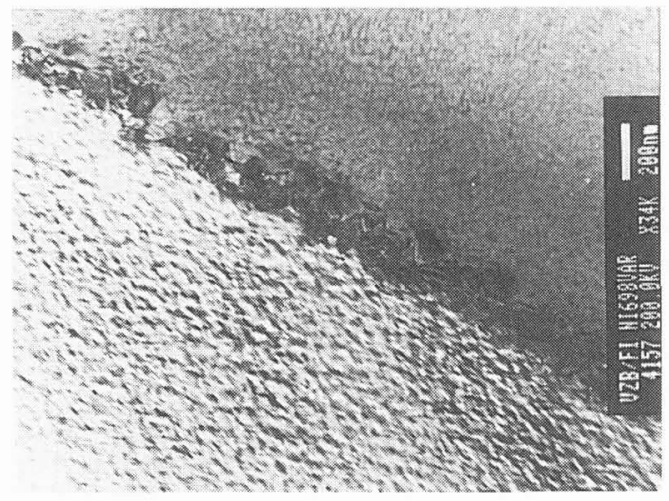

Fig.3 Microstructure of state 4

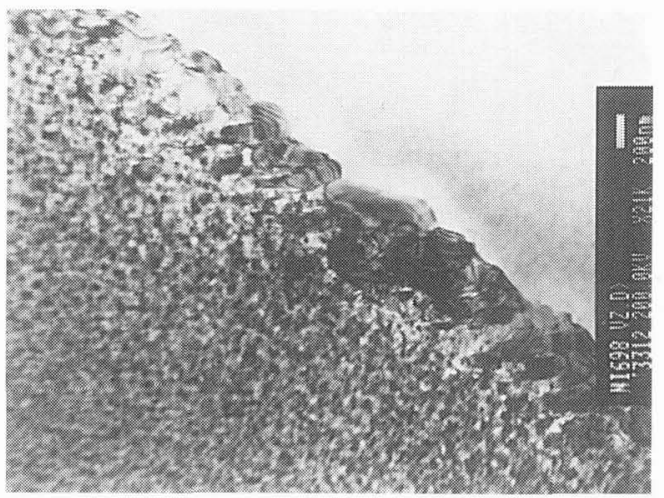

Fig. 5 Microstructure of state 3

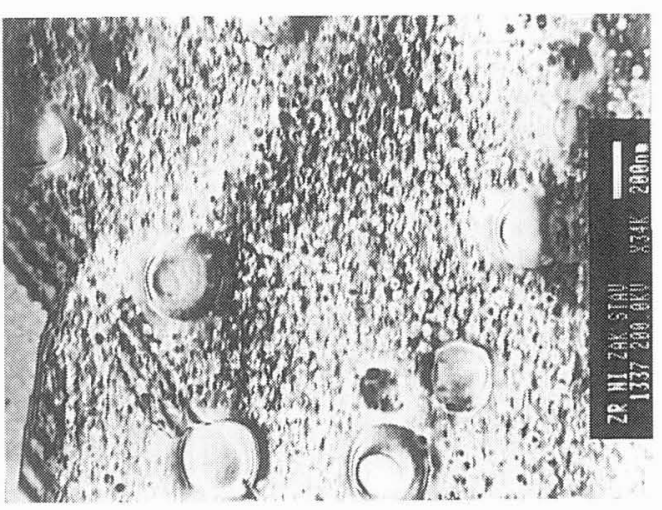

Fig.2 Microstructure after idustrial heat treatment

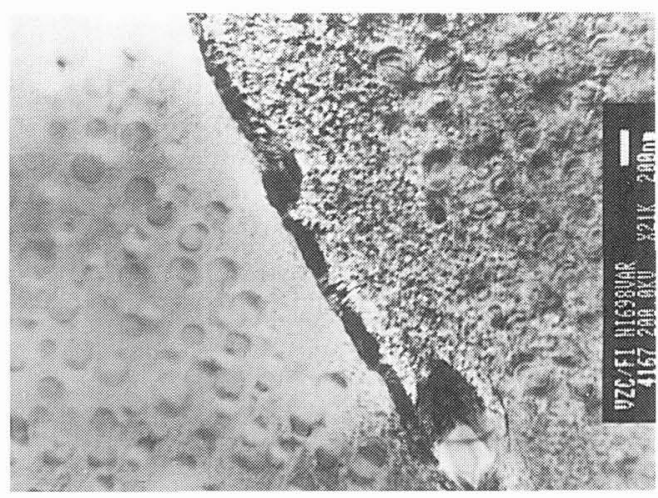

Fig.4 Microstructure of state 5

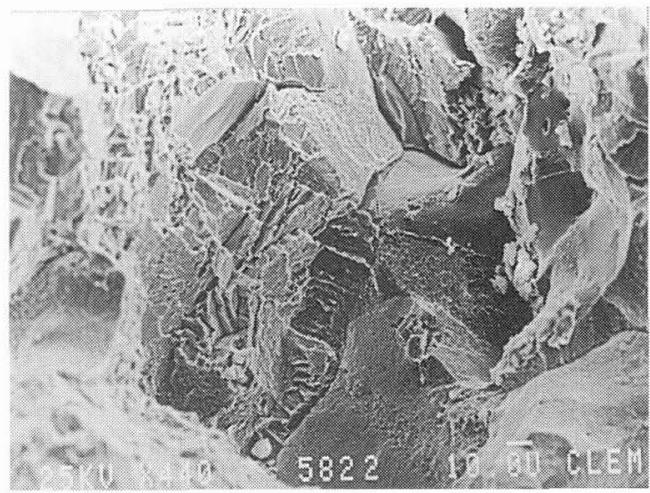

Fig.7 Morphology of ruptured surface 


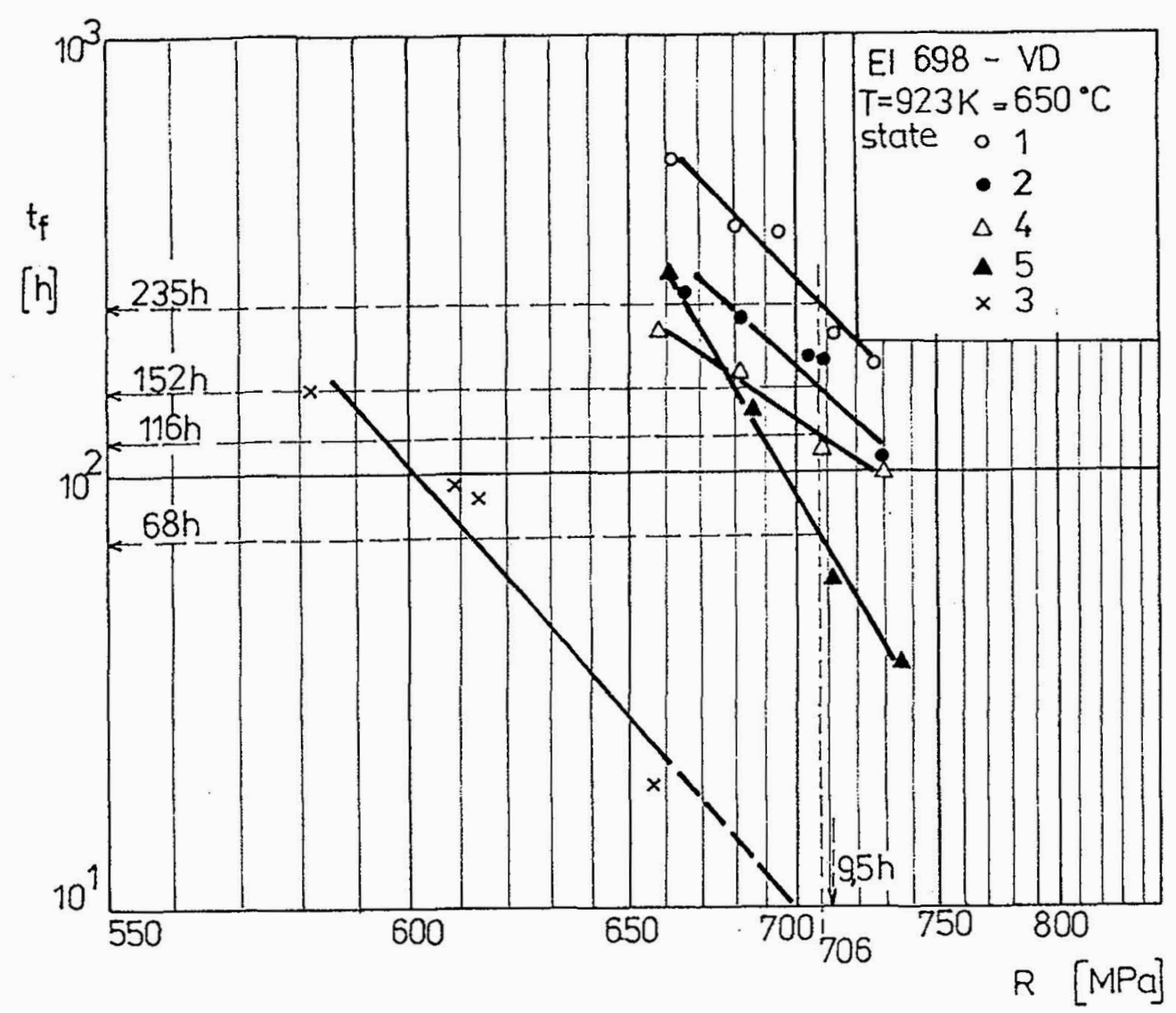

Fig. 6 Effect of applied stress on the lifetime

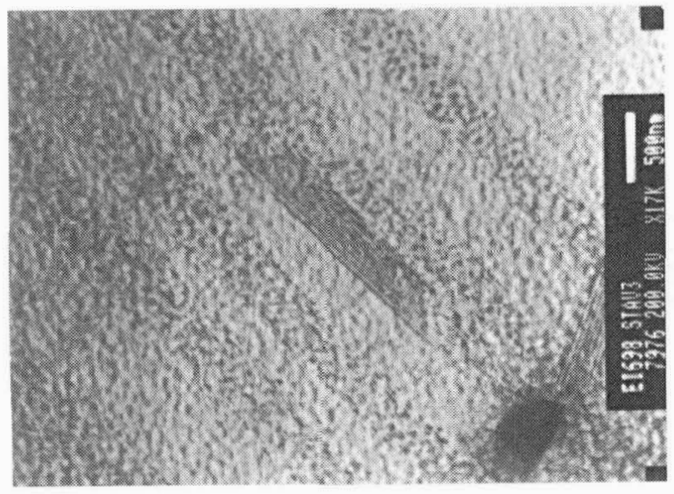

Fig.8 SIip bands close to Fracture surface

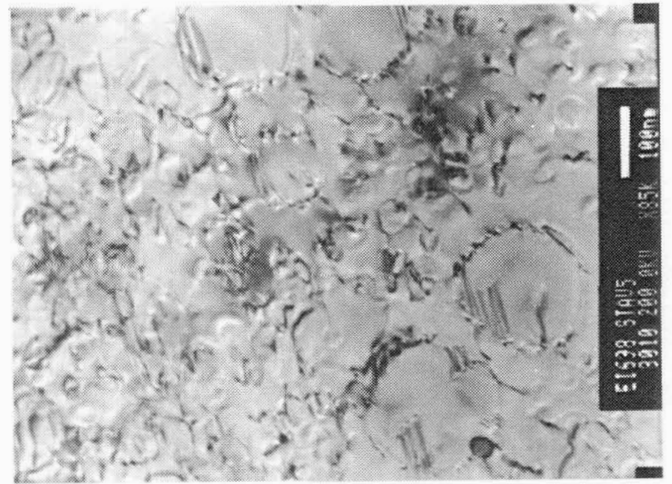

Fig.9. Dislocations/particle 